\title{
Educación, racismo cultural y seguridad nacional: la escuela intercultural en contextos de violencia ${ }^{1}$
}

\author{
Patricio Lepe-Carrión²
}

\section{Resumen}

El artículo recoge conclusiones parciales de un proyecto en curso, financiado por Fondecyt ( $\left.n^{\circ} 11140804\right)$ y Becas-Chile, y patrocinado por la Universidad de Chile, Universidad de Sao Paulo, y Universidad de La Frontera. Tiene como objetivo analizar el discurso educativo intercultural en contextos de violencia, tomando como foco específico de estudio, la función que la escuela intercultural cumple al interior del conflicto armado que el Estado chileno mantiene con el pueblo mapuche en la región de la Araucanía. La perspectiva teóricometodológica utilizada es el Análisis del Discurso desde las contribuciones y posibilidades abiertas por el filósofo Michel Foucault, tomando como archivo de análisis dos tipos de muestras: documentales y etnográficas; las primeras, recopiladas desde los años 1990-2016; y las segundas, adquiridas en el transcurso de los último dos años (20152016). En la primera parte, intentaré visibilizar aquellas prácticas no-discursivas implicadas en la desestabilización del modelo extractivista y monoexportador en Chile, y de sus efectos en la militarización de la región de la Araucanía. Luego, describiré brevemente las características de la racionalidad etnogubernamental que opera en los discursos y prácticas multiculturales en post-dictadura, para después mostrar el modo en que funcionan los procesos de etnicidad en los programas educativos sobre interculturalidad. En la última parte, a modo de conclusión, formularé algunas reflexiones que pretenden establecer vínculos entre los programas de educación intercultural, culturalismo o racismo cultural, gubernamentalización del Estado, y estrategias securitarias de percepción y construcción del enemigo interno.

\section{Palabras clave}

Educación - Interculturalidad - Racismo - Violencia - Pueblo Mapuche.

1- Este artículo se basa en resultados parciales que el autor ha obtenido de su proyecto financiado por Fondecyt de Iniciación No11140804: Educación y racismo cultural: evidencias y discursividades en los agentes que implementan el Programa de Educación Intercultural Bilingüe (PEIB), del Departamento de Estudios Pedagógicos de la Universidad de Chile; en conjunto con el proyecto de postdoctorado (Becas-Chile): Neorracismo y procesos de gubernamentalidad en los programas sobre educación intercultural en Chile, de la Faculdade de Educação da Universidade de São Paulo (Brasil); y con el proyecto de postdoctorado Educación, racismo y dispositivos de seguridad nacional: función del discurso pedagógico intercultural en contextos de violencia y resistencia territorial en la Región de la Araucanía, del Núcleo de Ciencias Sociales y Humanidades de la Universidad de La Frontera.

2- Universidad de La Frontera, Temuco, Wallmapu-Chile. Contacto: patriciolepe@gmail.com 


\section{Education, cultural racism and national security: the intercultural school in contexts of violence}

\section{Abstract}

The article collects partial conclusions of an ongoing project, financed by Fondecyt $\left(n^{\circ} 11140804\right)$ and Becas-Chile, and sponsored by the University of Chile, University of Sao Paulo, and the University of La Frontera. Its objective is to analyze the intercultural educational discourse in contexts of violence, taking as a specific focus of study the function that the intercultural school fulfills within the armed conflict that the Chilean State maintains with the Mapuche people in the Araucania region. The theoreticalmethodological perspective used is the Discourse Analysis from the contributions and possibilities opened by philosopher Michel Foucault, taking as a file of analysis two types of samples: documentary and ethnographic; the first, collected from the years 19902016; and the second, acquired during the last two years (2015-2016). In the first part, I will try to make visible those non-discursive practices involved in the destabilization of the extractivist and mono-exporting model in Chile, and its effects on the militarization of the Araucania region. Then, I will briefly describe the characteristics of ethnogovernmental rationality that operates in multicultural discourses and practices in postdictatorship period, and then show how ethnicity processes work in educational programs on interculturality. In the last part, as a conclusion, I will formulate some reflections that intend to establish links between intercultural education programs, culturalism or cultural racism, governmentalization of the State, and security strategies of perception and construction of the internal enemy.

\section{Keywords}

Education - Interculturality - Racism - Violence - Mapuche People.

\section{Introducción}

Muchos de los problemas que asociamos de manera muy ambigua y generalizada al racismo están imbricados en una red más compleja de relaciones de poder, donde la escuela, los programas y sus respectivas prácticas pedagógicas en contexto intercultural, se constituyen en piezas fundamentales dentro de un escenario económico y securitario.

Mi acercamiento a este problema, que podríamos enmarcar -inicialmente- en lo que algunos autores han denominado como neo-racismo (BARKER, 1981; WALLERSTEIN; BALIBAR, 1991), racismo diferencial (TAGUIEFF, 1991) o fundamentalismo cultural (STOLCKE, 1995), lo abordaré mediante un análisis del discurso que considera las 
contribuciones y posibilidades del pensamiento arqueo-genealógico del filósofo francés Michel Foucault (2000, 2002, 2014a, 2014b, 2014c). El archivo en el cual sustento este trabajo se compone de dos tipos de muestras. Una de ellas es de carácter documental, y está formado por leyes, normativas, declaraciones públicas, actas del gobierno, recortes de periódicos, etc., relativas a un discurso que se reconoce a sí mismo como intercultural; y el otro tipo lo constituyen una serie de entrevistas y observaciones al interior de la comunidad educativa en escuelas con mayoría de matrícula indígena (mapuche) en la región de la Araucanía, y que se encuentran al centro de un conflicto armado, que en las últimas tres décadas ha tomado una forma de despliegue muy particular, e intensificado con el desarrollo de una lógica gubernamental neoliberal de acelerada expansión a partir de los primeros años que sucedieron a la dictadura militar ${ }^{3}$.

Por razones de espacio, y por tratarse de un proyecto inacabado, me limitaré a señalar uno de los puntos centrales en este tipo de análisis del discurso: intentaré describir en términos de discontinuidad la historicidad del conflicto señalado; es decir, no me remitiré a ningún relato con pretensión de verdad histórica, que prefiera sustentar su descripción sobre el supuesto encadenamiento de hechos que se remontan a la época de la conquista, la colonia, o a los primeros años de independencia nacional, de modo tal, que los problemas del ahora se muestren como el resultado necesario y contundente de una larga ecuación originaria. Si bien este conflicto tiene un nutrido expediente de experiencias traumáticas, complejas, y de resistencias no documentadas que fueron silenciadas por la sistematicidad de la exigencia científica de las épocas sucesivas, el archivo de este saber sometido -de la nación mapuche- estuvo custodiado bajo un código de tipo moral, de transmisión oral, familiar, y de guerra, que reaparece en distintos momentos de la historia, con distintos matices y vinculado permanentemente a lo que más adelante señalaré como condiciones vitales o de sobrevivencia.

Intentaré seleccionar algunos elementos dispersos y heterogéneos de nuestro presente, de aquella superficie de prácticas discursivas que remiten constantemente al pasado, pero que en su actualización resuenan las regularidades que permiten determinar algunas operaciones de dominación que van más allá de la mera expresión de un grupo social determinado o de la reproducción de un sistema de relaciones preexistentes. Es decir, trataré -como ya lo sugería Foucault en sus trabajos-, de encontrar allí, en esa superficie de positividades, las funciones que operan a un nivel de discurso, pero en tanto campo estratégico, donde tanto lo dicho como lo no dicho cuenten como partes constitutivas, y también constituyentes, de las relaciones sociales implicadas en el marco educativo actual.

\footnotetext{
3- El pueblo Mapuche es el grupo indígena más grande en Chile, vinculado estrechamente a la historia institucional del país, y a su actual estructura racista y clasista (LEPE-CARRIÓN, 2016). Los mapuche constituyen el sector más marginado, empobrecido y duramente reprimido por el Estado chileno durante décadas, a pesar de tener una de las culturas más ricas de toda América, con un fuerte arraigo histórico, territorial e identitario. La actual IX Región de la Araucanía se ubica en la parte oeste del Wallmapu (extenso territorio histórico mapuche que comprende desde el río Bíobio por el Norte, hasta las islas de Chiloé por el sur, hasta el lado ocupado por Argentina en el Este), y condensa, hoy en día, la mayor población indígena mapuche después de Santiago. El conflicto que mantiene el Estado con el pueblo Mapuche es complejo y se remite a muchos procesos diferentes durante el transcurso de casi dos siglos; pero es durante las últimas tres décadas que la expansión forestal, junto a una serie de factores que intentaré abordar brevemente, se abrió un nuevo flanco de desacuerdos, enfrentamientos, muertes, querellas, juicios, intervención policial, impacto y manipulación mediática, etc. Para una historia más detallada, véase Marimán y otros autores (2006).
} 
Valga señalar -sin embargo- que la relación que hago entre escuela, racismo y cultura en contextos de violencia, no tiene como objetivo central las estrategias metodológicas ni contenidos curriculares de los programas educativos por sí mismos; aunque puedan, eventualmente, desprenderse algunas reflexiones al respecto, sino más bien, mi intención tiene que ver con la inscripción de la escuela en ese campo de relaciones de poder específico: el control del conflicto étnico mediante dispositivos securitarios de enquistamiento cultural y económico, que tienen como foco de emergencia a la escuela y sus programas de educación intercultural ${ }^{4}$.

Por otro lado, contrariamente a la cientificidad que caracteriza a los estudios actuales sobre etnoeducación en Chile, y principalmente su pretendida neutralidad respecto a los procesos de despojo de tierras y la violencia sistemática a la que se enfrentan diariamente las comunidades mapuche, pienso que la escuela juega un rol insoslayable en la contingencia política y policial de la región de la Araucanía.

Un lugar común es pensar que hoy en día existe algo así como un racismo de Estado; y que el conflicto señalado no es más que un efecto del odio nacional, arrastrado desde la colonización y amparado por el brazo armado del Estado contra un grupo étnico determinado: los mapuche.

Es cierto que el racismo es constitutivo de la institucionalidad chilena, y que sin él no es posible pensar la estructuración desigual de clases en el presente. También es cierto que el pueblo mapuche ha sufrido distintas colonizaciones y reducciones a lo largo de la historia, tan crueles y despóticas, que se siguen reflejando en la práctica cotidiana de la policía y en los procesos jurídicos.

Sin embargo, el problema de la intensificación de la militarización en la región de la Araucanía durante las últimas tres décadas tiene también otros operadores o funciones que deberían ser analizados, y que -desde luego- están atravesados por un racismo histórico, pero no se reducen a cuestiones de superficie tan visibles o explícitas como aquellas de carácter sociológico y psicológico como la discriminación y los prejuicios, ni de tipo histórico-jurídicas como el actual nudo gordiano de tratados, títulos de Merced, expropiaciones y reducciones, o incluso de carácter político como los intereses expansionistas y de asentamientos forzosos avalados por el Estado chileno. Hay también otro tipo de funciones al interior del discurso etnogubernamental, otras formaciones discursivas que aparecen, se cruzan, se transforman a partir de una cuidadosa descripción de aquellas regularidades presentes en el archivo de aquellas prácticas.

Una formación de tipo económico-securitaria se deja entrever en el análisis que confronta los discursos provenientes del ámbito intercultural con aquellas prácticas nodiscursivas que tienen que ver con debates, pareceres, diferencias o decisiones respecto a la protección de capitales y/o de instituciones que están por sobre, y por fuera, del

4- Según el informe elaborado por Carabineros de Chile ante la Comisión de seguridad del Congreso Nacional, respecto al fenómeno violencia rural, la asignación de recursos en la Araucanía en dotación policial tuvo un aumento del 65,9\% desde el año 2005 a la fecha, es decir, un total de 1.250 efectivos. En cuanto a la asignación de vehículos, solamente entre el Biobío y la Araucanía se distribuyeron 50 carros blindados y 93 semi-blindados. Súmase a esto, la adquisición de alta tecnología de prevención, investigación y seguridad: implementación de sistemas georeferenciados, drones, aviones no tripulados, teléfonos satelitales, y radares de detección para ser instalados en las faenas forestales (CHILE, 2016). 
cuestionamiento público tales como la escuela, los programas de formación e intervención social, etc.

A continuación, me limitaré a establecer algunas relaciones entre elementos dispersos, que visibilizan claramente la emergencia de un conjunto de intereses, estrategias, tácticas, objetos de intervención, posicionamientos, etc., que conforman este campo de significaciones desde el cual es posible pensar el contexto donde se juega la funcionalidad del discurso etnogubernamental, y con ello la complejidad del entramado educativo intercultural.

\section{La crisis del modelo extractivista y monoexportador: militarizar la Araucanía}

Durante el año 2004 dos científıcos jóvenes (Andre Geim y Konstantin Novoselov) de la Universidad de Manchester, Inglaterra, acostumbraban realizar experimentos de laboratorio fuera de horario de trabajo los días viernes en la tarde. Mientras todo el mundo se iba directo a sus casas, ellos preferían ensayar con lo que les permitían sus conocimientos e imaginación. En una de esas tardes, usando una conocida técnica de exfoliación micromecánica, que consistía en pegar una cinta adhesiva en un grafito y luego arrancarla para obtener un grafito más puro, uno de los científicos decide analizar lo que restaba en la cinta. Al hacerlo, descubrieron que se trataba de un nuevo material compuesto de partículas de carbono e hidrógeno, que estructuradas en teselado hexagonal, le otorgaban una serie de impresionantes características: posee la espesura de un átomo; es doscientas veces más resistente que el acero, y más fuerte que el diamante; más flexible que la fibra de carbono; impermeable a gases tan ligeros como el helio; su transparencia permitía el traspaso del 97,5\% de la luz; su materia prima barata y abundante (carbono); su conductividad eléctrica es cien veces más rápida que el cobre, y pierde menos energía calórica al conducir los electrones (efecto joule), etc. Estas características, hacen del grafeno un material nanométrico bidimensional óptimo para el uso de pantallas sensibles (touch), para acelerar el internet hasta 100 veces, para la producción de sensores, dispositivos fotónicos, para la disipación del calor, la industria aeroespacial, naval y automotriz, para la biomédica (prótesis e implantes livianos y resistentes), las telecomunicaciones, la generación de energía, baterías, fotografías más sensibles, cables de alta velocidad, etc. El descubrimiento de este material les significó el reconocimiento internacional más anhelado por el mundo científico, el premio Nobel de Física 2010, además de los títulos de caballero otorgados por la corona británica (WOLF, 2014).

Los efectos comerciales de semejante descubrimiento no se hicieron esperar: a partir del 2007, la compañía Samsung comenzó a liderar mundialmente la investigación y desarrollo del material ${ }^{5}$ y en el 2012 ya se contabilizaban 7.351 patentes a nivel internacional en torno al grafeno y sus distintas aplicaciones, de las cuales más de 2.000 eran chinas,

5- Sin ir más lejos, recientemente (2 de marzo de 2016), la Universidade Presbiteriana Mackenzie (campus Higienópolis - São Paulo) acaba de inaugurar el Mackgraphe, Centro de Pesquisas Avançadas em Grafeno, nada más que con la presencia del mismo Andre Geim y recibiendo un aporte de 100 millones de reales. 
1754 de EEUU, y 1.160 de Corea del Sur ${ }^{6}$. Por otro lado, distintas empresas que se han vinculado con el nuevo material ya están viendo incrementadas sus acciones en la bolsa de valores; como por ejemplo: Oxford Instruments, Graphene Nanochem, Graphene 3D, Applied Graphene Materials, Northern Graphite Corporation, CVD Equipment Corporation (SELF BANK, 2016).

En resumen, lo que pretendo decir con esto, es que el cobre está pasando por una crisis que va más allá de una baja o alta respecto a la valoración internacional del dólar, o del pasajero fantasma del litio: estamos frente a una posible crisis que pondría fin a la era comercial del material rojo, del mismo modo que lo fue la del salitre a fines del siglo XIX.

El 30\% de la producción mundial del cobre está liderada por Chile, siendo la principal actividad económica del país. No sólo representa el 11,2\% del PIB total, y el 54,7\% de todas las exportaciones (CONSEJO MINERO, 2015), sino también la estabilidad de los servicios financieros, transporte, construcción, e incluso políticas monetarias, cambiaria y fiscal, o en el comportamiento macroeconómico (CONSEJO MINERO, 2015).

Lógicamente, la emergencia del grafeno es un asunto que no ha dejado indiferente a los expertos en tecnología y desarrollo en Chile. El mismo Consejo Nacional de Innovación para la Competitividad (CNID), organismo público-privado que busca asesorar directamente a la Presidenta de la República en identificar, formular y ejecutar políticas y acciones que fortalezcan la innovación y competitividad en Chile, en su informe anual del año 2013 señaló al grafeno "[...] como el más nuevo de los competidores serios y dignos de temer" (CHILE, 2013a, p. 50) respecto a la industria del cobre.

Un año más tarde, Rodrigo Rojas, asesor legal de la Asociación Chilena de Empresas de Tecnología e Información (ACTI) y expositor de la tercera reunión informativa sobre el Acuerdo Estratégico Transpacífico de Asociación Económica (TPP), señala enfáticamente que "[...] hay dos nuevos materiales que son el grafeno y el carbino, que pueden reemplazar al cobre. El pánico es que nos pase lo que nos pasó con el salitre y Chile se vaya a una crisis muy, muy grande. Si no ponemos atención a los nuevos temas, estamos liquidados" (CHILE. BIBLIOTECA..., 2014).

El mismo año, el diputado Gonzalo Fuenzalida Figueroa solicitaba al presidente de la Corporación Nacional del Cobre (Codelco) por intermedio de la Cámara de Diputados, que informara sobre "[...] el impacto que tendrá en la empresa estatal el producto denominado grafeno, una vez que salga al mercado" (FUENZALIDA FIGUEROA, 2014, p. 1). Ante la negativa de Codelco en dar una respuesta al oficio, y la insistencia de Fuenzaliza en el año siguiente (FUENZALIDA FIGUEROA, 2015), Codelco envía -recién en Julio de 2016-, un informe a la Cámara de Diputados señalando -por un lado- la incompetencia de un parlamentario para solicitar dicha fiscalización, y -por otro- argumentando que tanto la Corporación de Fomento de la Producción (CORFO) como Codelco Lab (Innovaciones en cobre S.A.) se encuentran trabajando en nuevos componentes compuestos, es decir, de cobre y grafeno, para enfrentar las nuevas demandas tecnológicas. Así y todo, Codelco no niega la amenaza, sólo se refiere a cómo su equipo de innovación está enfocado en la

6- Junto a la Unión Europea y Japón, constituyen los principales socios comerciales de Chile según el informe anual de Comercio Exterior (CHILE, 2015a). 
sofisticación del uso del cobre en relación a los nuevos materiales que están apareciendo en el mercado (CODELCO, 2016).

La preocupación del gobierno por la posible crisis del cobre ha hecho que durante los últimos años asistamos a un conjunto de estrategias que tienen como foco el fortalecimiento de aquellos mercados que vienen después del material rojo en la lista de exportaciones.

Tal como un grupo de parlamentarios señaló en el IX Comité de diálogo político entre el Congreso Nacional y la Asamblea Nacional Popular China en mayo de 2015, nuestro país está comprometido en "[...] incrementar la inversión y desarrollo de proyectos productivos a nivel de extracción de materias primas [...]” (PEILLARD, 2015, p. 3), dando con esto una garantía al país que mayor intercambio comercial tiene con Chile.

Hace algunos meses atrás, Jorge Pizarro, entonces senador y presidente de la Democracia Cristiana, uno de los partidos políticos más influyentes del país en materia económica, lo hacía aún más explícito:

[...] el desafío es buscar esa nueva fuente de riqueza que remplace paulatinamente al cobre de su rol central en nuestra economía exportadora, para así asegurar suficientes ingresos futuros para un país que tiene grandes compromisos sociales, la gratuidad en la educación es el ejemplo más claro. (PIZARRO, 2016, p. 9).

Si hacemos un ligero análisis de las propuestas de infraestructura competitiva que propone la Corporación Chilena de la Madera (CORMA), o al denominado enfoque intermodal ${ }^{8}$ que defiende la Cámara Marítima y Portuaria de Chile (CHILE. CÁMARA ..., 2015), -ambas en una perfecta armonía de objetivos, y la sorprendente recepción que han tenido éstas -durante los últimos años- en la burocracia gubernamental- comprenderíamos fácilmente que una de las nuevas fuentes de riqueza que el gobierno está potenciando y protegiendo está en manos de las empresas forestales, que constituyen -después del cobre- las más elevadas cifras de exportación junto a las pesqueras (CHILE, 2015a).

La mesa de desarrollo portuario para la construcción del Puerto de Corral (CHILE, 2013c), por ejemplo, o el acuerdo ferroviario (CHILE, 2013b), o el transporte de alto tonelaje en carreteras (CORMA, 2016) son proyectos que afectan directamente -y de manera positiva- los intereses forestales ${ }^{9}$.

Súmase a esto que los mismos agentes políticos comprometidos con la gestión de políticas públicas en torno al crecimiento del sector forestal están afectados por escandalosos conflictos de interés. Por ejemplo, el recién saliente Ministro de Transportes y Telecomunicaciones, Andrés Gómez-Lobo, pieza clave en este proceso de intermodalidad

\footnotetext{
7- La infraestructura competitiva, es un modelo para el incremento productivo propuesto por la CORMA, que consiste en la inversión de infraestructura vial y ferroviaria. La propuesta señala que aumentando el tonelaje límite de carga en los camiones y ferrocarriles, mejorarían notablemente los índices de productividad e innovación de Chile respecto al resto del mundo (CORMA, 2016).

8- El enfoque intermodal analiza el desarrollo de infraestructura e interacción entre los tres binomios modales básicos: transporte terrestre (carreteras, ferrovías), aéreo (aeropuertos), y marítimo (puertos).

9- Según el Plan presentado por Secretaría de Transportes, el tipo de mercado primordial en tres de los cinco segmentos planificados tiene que ver con la industria forestal: Alameda San Rosendo: Santiago-Chillán-San Rosendo; Red Región Bío-Bío: San Rosendo-Talcahuano-HorcónesLirquén; y Red Sur: San Rosendo-Puerto Montt (CHILE, 2013b).
} 
e infraestructura competitiva que insistentemente ha propuesto la CORMA durante los últimos años, según su declaración patrimonial del 2014, estaría fuertemente vinculado como accionista en las empresas relacionadas a la familia Matte: Compañía Manufacturera de Papeles y Cartones (CMPC) y Forestal, Constructora y Comercial del Pacífico Sur S.A. (PASUR). No es de extrañar que en julio de 2014, cuando el ministro asumía la cartera, declarara en una entrevista a diario La Tercera (ORTIZ, 2014) que una iniciativa para mejorar el desempeño logístico del país, era justamente el enfoque intermodal que favorecería la exportación de materias primas.

La actividad forestal en Chile representa la tercera actividad económica más relevante en exportaciones, llegando a la cifra de 6.094 millones de dólares en el 2014; es decir, un 8,1\% de las exportaciones del país. El aporte que hace el sector forestal al PIB es de aproximadamente 2,7 billones de pesos anuales, equivalentes al 2,7\% del PIB del país. Se calcula que aporta con el 4\% del empleo nacional, de los que unos catorce mil empleados aproximadamente corresponderían solamente a la región de la Araucanía.

En cuanto a la participación de Chile en el extranjero en el ámbito forestal, pertenece a los veinte primeros países productores y comercializadores de recursos forestales. Onceavo lugar en la producción de madera en trozas, décimo en pulpa de madera, decimotercer lugar en madera aserrada, y décimo octavo lugar mundial en plantación de bosques.

Lógicamente, y considerando estos datos, el lector podrá comprender con mayor claridad por qué el Estado adopta medidas de seguridad nacional tan brutales en la Araucanía (y el Bíobío) durante los últimos años ${ }^{10}$.

La actividad económica de las forestales debe ser protegida ante una eminente desestabilización en la producción del cobre.

\section{Racionalidad etnogubernamental11}

Ahora bien, cabe preguntarse qué tiene que ver todo esto con la educación, y específicamente con la educación intercultural.

Durante la post-dictadura, en los sucesivos gobiernos de la Concertación ${ }^{12}$, comienzan a aparecer una serie de debates en torno a la deuda histórica que tiene el país con las etnias originarias, que tendrán como consecuencia una serie de acuerdos donde se ha evidenciado un conjunto de demandas en torno al territorio, al reconocimiento, a la autonomía y a los derechos culturales y lingüisticos (MARIMÁN et al., 2006; PAIRICÁN; ÁLVAREZ, 2011).

Los primeros debates en torno a la cuestión indígena, durante el gobierno de Patricio Aylwin (1990-1994), van a sedimentar en la Ley indígena $n^{\circ}$ 19.253 (CHILE,

10- Cabe señalar que las prácticas racistas, problemas territoriales, medioambientales, militarización, que en su conjunto podrían formar parte de la emergencia histórica de la seguridad nacional, son muy anteriores a la dictadura de Pinochet. Mi descripción y análisis se limita a la función del discurso educativo intercultural cuando -en postdictadura- entra en juego con prácticas no-discursivas sobre la economía política de la población en contextos de violencia policial.

11- Sobre éste y el próximo apartado (Educación intercultural y el problema del multiculturalismo), aunque con un enfoque diferente, en la producción y gestión de identidades, puede consultarse Leppe-Carrión (2015).

12 - Coalición política que reúne a partidos de izquierda y centro, que gobernó desde el término de la dictadura hasta la fecha (hoy bajo el nombre de Nueva Mayoría). Entre los años 2010-2014 hubo un solo gobierno de centro-derecha. 
1993) que reconoce y promueve la diversidad cultural y crea al mismo tiempo mecanismos de interacción entre el Estado y los pueblos indígenas (BOCCARA; BOLADOS, 2010). Por ejemplo, la Corporación Nacional de Desarrollo Indígena (Conadi) es un producto de la mencionada ley y hoy constituye uno de los estamentos más relevantes en la promoción, coordinación y ejecución de las políticas referidas a los pueblos indígenas.

A partir de entonces y primeramente con el Programa de Desarrollo Integral de Comunidades Indigenas (Orígenes) financiado a través de un préstamo al Banco Interamericano del Desarrollo y otro tanto por el Ministerio de Educación (Mineduc), y cuya primera fase comenzó a operar desde el año 2001, se despliega un amplio operativo gubernamental que busca la inclusión de los pueblos originarios a través de su participación comunitaria, salud y educación intercultural. Con el correr de los años, se fue consolidando cada vez más la preocupación y auto-exigencia del gobierno en convertir a Chile en un país pluricultural y multiétnico. La institucionalización del discurso sobre lo intercultural se hizo cada vez más evidente en la retórica de los agentes estatales y paraestatales; la propia presidenta Michele Bachelet, en su primera administración del año 2008, hablaba de un Pacto social por la multiculturalidad, el cual consistía en el reconocimiento de un desgaste de los pactos que los gobiernos anteriores tuvieron con los pueblos originarios, y anunciaba un nuevo plan de acción en torno a la revisión del sistema político, derecho, e institucionalidad. 0 más reciente aún, en su segundo mandato, la misma presidenta en su discurso presidencial del 21 de mayo de 2014, declara su intención por establecer una educación de calidad, en la cual "[...] todas y todos los estudiantes sean formados para ser ciudadanos interculturales” (CHILE, 2014, p. 240). E incluso, durante el último discurso presidencial señala que Chile es una nación multicultural (CHILE, 2016).

Esta preocupación del Estado por la cuestión multiétnica, donde los pueblos indígenas aparecen como una población sujeta a necesidades y aspiraciones, y al mismo tiempo, donde la vida de los mismos es objeto de intervención mediante saberes expertos en asuntos indígenas y técnicas de conducción de sus conductas identitarias (LEPECARRIÓN, 2015), tiene como correlato la consolidación de un dispositivo de seguridad nacional que tiene como objetivo la identificación del enemigo interno mediante la configuración de etnicidad con fines estratégico-militares. Dicho dispositivo tiene -a mi juicio- un incipiente, aunque relevante, espacio de formación en la escuela y en su desinstitucionalización; donde la negación, jerarquización y relativización de trazos culturales ha dado lugar al encubrimiento de la diferencia racial que subyace en el amplio y generalizado cuadro de representaciones sociales.

\section{Educación intercultural y el problema del multiculturalismo ${ }^{13}$}

La educación intercultural emerge en el marco de una prometedora Reforma Educacional (GARCÍA HUIDOBRO; COX, 1999) que se proponía completar las falencias

\footnotetext{
13- Notará el lector, que el problema del multiculturalismo, se refiere a que la idea de interculturalidad barajada por el Ministerio de Educación no considera el pensamiento de los pueblos indígenas al respecto, sino más bien, como explicaré en este apartado, se alinea con aquellas directrices transnacionales del etno-desarrollo.
} 
que tenían los planes y programas vigentes respecto a la nula adaptación del currículo escolar a los contextos indígenas ${ }^{14}$.

A partir de entonces, el Programa de Educación Intercultural Bilingüe (PEIB) ha tenido un alcance territorial insospechado; lo que indudablemente, para los ojos del multiculturalismo, refuerza e institucionaliza con mayor vigor la preocupación por la cuestión indígena en las estrategias gubernamentales. El Programa de Educación Intercultural Bilingüe (PEIB) se ha convertido en un brazo operacional fundamental en las políticas sociales (CHILE, 2011; WILLIAMSON, 2012), pero no sólo en conexión con los problemas de segregación en Chile, sino, y principalmente, en sintonía con los flujos culturales transnacionales de reconocimiento de la diversidad y del etnodesarrollo (APPADURAI, 2001; HANNERZ, 1998).

Pero ¿cuál es el problema de esta visión sobre la interculturalidad emparentada con las políticas multiculturales? ¿cuáles son sus efectos de etnicidad cuando entran en relación con prácticas no discursivas como son los procesos políticos y económicos que he descrito brevemente en la historia sobre el grafeno?

Lo que estoy problematizando es que el multiculturalismo es funcional a esas políticas neoliberales extractivistas y de monoexportación, puesto que tienen como efecto inevitable el control y dominio de la hegemonía nacional mediante la construcción de categorías que tipifican y segregan en torno a un diferencialismo cultural que sedimenta en la clasificación de formas aceptables y no aceptables de ser mapuche.

Las acciones afirmativas del multiculturalismo, aunque necesarias, no dejan de ser, en la mayoría de los casos, una herramienta de discernimiento por parte de quienes agencian las políticas públicas en educación, que les permiten distinguir y definir aquellos derechos culturales que están en sintonía con el ideal de una democracia plural y liberal, de otros derechos reivindicativos que están por fuera de aquel ideal de democracia, o que simplemente le son antagónicos. De modo que aquellos que se pronuncien en contra de las inequidades, de las injusticias, o de las demandas históricas por las condiciones vitales de sobrevivencia, puedan ser considerados, en nombre de una ética universal, como subversivos, radicales, intolerantes, extremistas o en el peor de los casos, como terrorista (HALE, 2007).

La escuela y sus respectivos programas multiculturales no puede ser vista como un espacio neutral o al margen de las demandas de reivindicación territorial y de autonomía, puesto que son lugares estratégicos de una eventual resignificación y folclorización de la cultura; son campos de disputa, donde las identidades son producidas y transformadas de manera continua conforme a las contingencias históricas que predisponen diferentes escenarios de lucha.

Últimamente ha habido un fundamentalismo cultural y lingüístico que ha desembocado en aquella divulgada idea de que se hace interculturalidad cuando se saturan los programas educativos con valoraciones excesivas de contenidos que terminan siendo folclorizados (festividades, vestuario, cuentos, danzas, comidas, etc.), o de pensar que

14- Las críticas al antiguo modelo educativo se venían expresando desde mucho antes (la década del 20), cuando un número significativo de dirigentes indígenas, profesores e intelectuales creían necesaria la adaptación del currículo. La conquista de espacios relacionados al contexto educativo se ha abierto gracias a la lucha permanente de agrupaciones y sectores mapuche (CAÑULEF, 1998; QUINTRIQUEO et al., 2014). 
únicamente revitalizando la lengua, o haciendo un uso permanente de ella en los textos escolares se está construyendo una visión intercultural de la educación.

El vaciamiento de la cultura y lengua indígena en contextos educativos, el distanciamiento con la formación familiar y tradicional de las comunidades que la transmiten, o en otras palabras, la sustracción de aquella de las cosmovisiones y filosofías que le son propias, trae como consecuencia un nuevo despojamiento de las concepciones más arraigadas que dan un completo sentido a las demandas históricas; cosmovisiones y filosofías que justamente son el núcleo de la resistencia y creatividad que como pueblo han mantenido durante siglos frente a la colonización.

Un despojamiento de los derechos culturales que no necesariamente coinciden con los ideales de la democracia neoliberal a la cual se les obliga a participar, porque debemos aclarar, que la interculturalidad gubernamental nunca ha sido recíproca, es decir, si el chileno elige ser un ciudadano intercultural en tanto opta por conocer o no el mundo mapuche, su lengua, o su cultura, el mapuche es obligado a integrarse a la cultura occidental, y desde allí, obligado nuevamente a revalorizar la cultura de sus antepasados; esto es, no existe reciprocidad o simetría en el diálogo e intercambio: se trataría de una especie de interculturalidad unilateral que atenta al principio de no-contradicción implicado en su definición.

La revalorización de la cultura a la que se ve permanentemente enfrentado el pueblo mapuche, principalmente mediante la escuela como foco de transvaloración, conlleva necesariamente un despojo de las visiones de mundo que son trascendentales en la vida misma de los sujetos que la experimentan. Concepciones de mundo que son probablemente antagónicas al modelo de país monocultural y etnocida que se ha implementado en Chile desde la formación del Estado-nación (LEPE-CARRIÓN, 2016): visiones sobre la tierra, la familia, la transmisión oral, el gobierno, Dios, obligaciones morales, etc., son -desde luego- un soporte socio-ético de vital importancia sobre el cual se constituyen los distintos modos de subjetividad mapuche. No otro ha sido el fundamento filosófico de la histórica causa reivindicativa que hasta el día de hoy nos interpela desde el Wallmapu (CAM, 2013; LLAITÚL; ARRATE, 2012; MARIMAN, 2012; MARIMÁN et al., 2006).

La visiones de mundo mapuche son antagónicas al Estado chileno que legitima las prácticas de usurpación, justamente porque vienen a desmantelar la estructura institucional, económica y hegemónicamente racial, mediante la imperiosa exigencia de condiciones vitales que son esenciales para la sobrevivencia y desarrollo de una etnia: a) reivindicación del espacio territorial usurpado con las prácticas colonialistas; b) la plena legitimidad como interlocutores jurídicamente válidos; c) autonomía política en la administración de la justicia, de la salud, de la educación, de sus sistemas tributarios, etc.; y d) la adquisición de derechos culturales y lingüísticos que articulen y otorguen coherencia identitaria a estas demandas (VARESE, 1982).

El vaciamiento al que hago referencia es -como ya habrá percibido el lector- una forma de encubrir la diferencia racial que posibilita la explotación mediante relativizaciones culturales que socaban en la formación de subjetividades. Es decir, que los nuevos modos de producción extractivista exigen la reducción de los modos de existencia mapuche a esencialismos, a folclorización de su cultura, a exotismo y musealización de los íconos que 
reducen y aíslan sus expresiones culturales más profundas (KYMLICKA, 2003; TRAPNELL; NEIRA, 2004; TUBINO, 2005).

Lo interesante de este proceso de etnización o culturalismo que se describe aquí no es solo que se tiende a despolitizar el proceso educativo, sino que la promesa multicultural se hace exclusiva para los indígenas y no para la sociedad en su conjunto; esto es, se entiende al ciudadano intercultural como a un sujeto nacional homogeneizado. Las categorías de raza o de racismo que operaban como indicadores de diferenciación a comienzos del siglo XX, o incluso antes (LEPE-CARRIÓN, 2012a, 2012b, 2016), son reemplazados por una retórica de la inclusión y exclusión por "[...] diferencia de identidad cultural, tradiciones y herencia [...]" (STOLCKE, 1995, p. 2); es decir, ha emergido una serie (siempre nueva y mutable) de indicadores o criterios de discernimiento entre lo diferente y lo semejante (ellos y nosotros) que colocan el acento en los rasgos culturales.

La cultura se está pensando aquí desde una perspectiva metacultural (BRIONES, 1998), es decir, más allá de lo que comúnmente se podría interpretar en relación al conjunto de acciones de un determinado grupo humano, o de los modos en que realizan dichas acciones; sino más bien desde aquellas propiedades que influyen más intensamente en la construcción de etnicidad (hegemonía), a saber, en su condición histórica de mediación y producción de sí misma. Las representaciones sociales o la misma diferenciación cultural son posibles gracias a esta doble cara de la cultura, tanto como proceso social de significación, pero al mismo tiempo, como productora de regimenes de verdad que le conceden la facultad de determinación de lo que es o no cultural (BRIONES, 1998), o de cómo es la cultura misma la que formula permanentemente una serie de indicadores o categorías de diferenciación, en las que se arraiga dicho fundamentalismo.

\section{Consideraciones finales: la etnicidad geoestratégica}

Los programas de educación intercultural son producto de un complejo ensamble de diferentes dispositivos muy heterogéneos que, si bien es cierto, emergieron y se han configurado desde los primeros años de la conquista y colonia hasta la fecha, han pasado por diversos modos de articulación que deben ser estudiados en su especificidad histórica, puesto que es allí, en su discontinuidad, donde se juegan las preguntas radicales que colocan a la educación bajo la mirada crítica de quienes implementan los programas en el aula: ¿Qué continuidades son posible rastrear entre la dominación colonial y nuestro presente? ¿Cuáles han sido los procesos de montaje de esta máquina educativa? ¿Para qué sirve este conjunto de programas sobre educación intercultural? ¿A quiénes sirve? ¿A qué sistemas de poder están ligados? ¿Cómo se transforman y disfrazan? ¿Cómo contribuyen a hacer posibles nuestras condiciones actuales de existencia? (ALVAREZ URIA; VARELA, 1991).

Para responder a estas interrogantes, es necesario que los agentes que implementan el Programa de Educación Intercultural Bilingüe (PEIB), reconozcan los dispositivos de saber/poder o conocimiento experto con los que interviene el gobierno, con los que se organiza, jerarquiza y legitima el discurso sobre lo intercultural. Es necesario que los agentes trabajen sobre la base de una interculturalidad que sea crítica respecto a los problemas del multiculturalismo global que ya se ha señalado, que desmantele la 
funcionalidad económica del poder, que les permita identificar qué idea de cultura se está barajando en la retórica de la gubernamentalidad, y en qué medida esta idea puede volverse un instrumento de diferenciación étnica; o cuáles son las representaciones sociales sobre lo originario, indígena, tradicional, patrimonial, auténtico, que se están produciendo en los dispositivos etnogubernamentales (LEPE-CARRIÓN, 2015).

La institución escolar opera con un diferencialismo cultural que tiene poderosos efectos de etnización en la sociedad; es decir, efectos que se traducen en la formación de subjetividades o sujetos políticos deseables, y a partir de ahí, en la tipificación de grupos potencialmente peligrosos, con sus respectivas representaciones o imágenes que se construyen a partir de aquellos criterios o regímenes de verdad.

En este sentido, es necesario también preguntarse sobre el rol que cumple la escuela en un contexto de violencia (física y simbólica) como el que ejercen las empresas forestales, el Estado y otros organismos (militarizados) sobre algunos sectores de la población. ¿Cuál es la filiación que existe entre los programas de etnodesarrollo, y otras tácticas utilizadas para el control del denominado conflicto étnico?

Esta pregunta es de especial relevancia, puesto que reviste un hallazgo de relaciones entre diversos mecanismos de gestión identitaria, que tienen como trasfondo una gubernamentalización del Estado (FOUCAULT, 1999), pero no en el sentido asistencial y/o represivo, como si de un despliegue de fuerzas opresoras y vigilantes de tratara, sino más bien, en un sentido de responsabilidad social corporativa y empresarial, donde el bienestar de todos los ciudadanos (incluyendo el cuidado del medioambiente) constituye una meta prioritaria de la que todos los organismos paraestatales también se hacen cargo.

El despliegue hacia el exterior de la escuela, aquella tendencia de ampliar sus alcances de integración hacia nuevas maneras de organizar a la comunidad por fuera de los límites institucionales podría ser un aspecto característico en la gubernamentalización del Estado (FOUCAULT, 2006); esto es, que la interculturalidad, siguiendo el modelo multicultural global, y sus principios de pedagogización en la comunidad, trasciende el espacio cerrado de la escuela y entra en un diálogo con recursos de acercamiento, comprensión e identificación que utilizan -instrumentalmente- estamentos corporativos que tradicionalmente han sido considerados como exógenos a los grupos que son objeto de sus políticas. Por ejemplo, la relación que existe entre los programas de educación intercultural del Ministerio de Educación con los programas de sustentabilidad creados por los departamentos de Responsabilidad Social Empresarial de las grandes corporaciones forestales. Se nota que son extrañamente compatibles, tanto en contenidos curriculares como en la particular codificación en que están escritos. No quiero decir que por el sólo hecho de ser compatibles sean peligrosos, se trata más bien de levantar una legítima sospecha, luego de realizar una mirada sinóptica, cuando se tiene en consideración por un lado- el vaciamiento cultural que señalé más arriba, y por otro, el fundamento desarrollista que sustenta dichos programas.

Véase, por ejemplo, el Modelo Forestal Intercultural Mapuche (MOFIM) (ÁLVAREZ; AQUILERA, 2011) que hace algunos años viene siendo incorporado por diferentes departamentos de Responsabilidad Social Empresarial y Corporativa en distintas empresas y organizaciones en las regiones del Biobío, Araucanía, Los Ríos y Los Lagos. El MOFIM, 
al igual que el Modelo Ambiental Intercultural Andino (MAIA) incorporado en la macrozona Norte del país, tiene como objetivo práctico la reforestación de las tierras mediante el financiamiento de proyectos comunitarios que se adecúen a la retórica multicultural y medioambientalista. No cabe cuestionar aquí este modelo, pero vale señalar que se trata de una lógica marcadamente desarrollista (ESCOBAR, 2014); esto es, que si bien amplía el espectro de desarrollo hacia la cultura, con lenguajes técnico-locales (uso del mapudungun), cuidado del medioambiente, rituales y estéticas folclorizantes que humanizan la actividad forestal, se mantiene casi intacta la estrategia de modernización liderada por grupos de expertos (cooptación de líderes locales) que avalan la acción extractivista de las empresas forestales instaladas en territorio mapuche (MARIMÁN et al., 2006).

Otra compatibilidad operativa o funcional al neo-desarrollismo multicultural que podría caer bajo una mirada de sospecha son los criterios de distinción cultural utilizados por los dispositivos de seguridad nacional para detectar y tipificar un determinado modo de experimentar, de sentir, o de pensar la vida mapuche que no esté en sintonía con el ideal democratizador y homogeneizante de la nación chilena (LEPE-CARRIÓN, 2016). Me refiero específicamente a los criterios culturales utilizados por la fuerza policial y judicial en su clasificación del sujeto terrorista.

Para que un cuerpo de seguridad ejerza su violencia contra un determinado grupo étnico no basta una orden superior de ataque, se requiere de procesos más extensos y complejos de subjetivación o de pedagogización policial, en que sean asimilados aquellos elementos que distingan con certeza al buen mapuche del mapuche delincuente. Aquí no hay lugar a equívocos; no se trata de distinguir por delitos cometidos, como se realizaría con cualquier ciudadano chileno, se trata más bien de hacer coincidir los gestos, palabras, vestuarios, y acciones folclorizadas, con seguimientos rutinarios de sujetos en territorio de violencia rural, que luego se archivan, asocian y esquematizan como comportamientos que permitan detectar anomalías para la prevención de acciones que pongan en riesgo la seguridad nacional. En esto consiste, o más bien, a esta dinámica responde la formación culturalista implementada en el curso sobre Estrategias Tácticas en Operaciones Rurales que imparte Carabineros de Chile a los funcionarios especializados de la zona de violencia rural, donde lo que se propone, entre otras cosas, es: “[...] interiorizar al personal [...] de algunos aspectos de la cultura mapuche que son importantes de conocer e internalizar para comprender su actuar" (CHILE, 2015b, p. 34).

Me da la impresión que los elementos de distinción que forman parte de aquellas construcciones identitarias y delictuales provienen en gran medida de los recursos pedagógicos y folclorizantes derivados del proceso histórico de homogenización nacional, que durante las últimas décadas ha desplazado al Estado hacia otros lugares de enunciación que antes eran impensados.

El punto de intersección entre los múltiples y variados elementos que conforman esta matriz securitaria, lo podríamos localizar en el concepto mismo de nación, que ha sido el soporte histórico desde el cual se destila -en las distintas capas de la historia- la raza como una categoría bioeconómica, hacia una idea de cultura que opera como mecanismo de inscripción de las personas en una determinada estructura de clase (MBEMBE, 2014).

Los discursos que se instalan con las políticas multiculturales en Chile a partir de la década de los 90 sólo se desvelan en su funcionamiento estratégico una vez que entran 
en juego o vinculación recíproca con las prácticas políticas y económicas de protección de capitales. Dicha función no es otra que la transformación de seres humanos en sujetos identificables y escindidos en mapuche cualificable/mapuche sospechoso, y abiertos a su exploración como objetos de un dispositivo que de momento puedo denominar como etnicidad geoestratégica; es decir, un campo de análisis que permite establecer como blanco de intercepción al sujeto singularizado a partir de una trama cronológica de actividades que giran en torno a las condiciones vitales de un colectivo identitario. En lo micropolítico, indudablemente se traduce en una red de prejuicios racistas, pero, en el ámbito nacional, dicha trama de subjetividad pone en riesgo no sólo los privilegios de un determinado grupo social, sino también la estabilidad de un país que tiene como motor de su economía la extracción indiscriminada de recursos naturales en desmedro de un irreparable daño social y medioambiental.

\section{Referencias}

ÁLVAREZ, Katherine; AQUILERA, Guido (Ed.). Modelo Forestal Intercultural Mapuche (MOFIM). Temuco: Corporación Nacional Forestal (CONAF), 2011.

ALVAREZ URIA, Fernando; VARELA, Julia. Arqueología de la escuela. Madrid: La Piqueta, 1991.

APPADURAI, Arjun. La modernidad desbordada: dimensiones culturales de la globalización. México, DC: Trilce: Fondo de Cultura Económica, 2001.

BARKER, Martin. The new racism. London: Junction Books, 1981.

BOCCARA, Guillaume; BOLADOS, Paola. ¿Qué es el multiculturalismo? La nueva cuestión étnica en el Chile neoliberal. Revista de Indias, Madrid, v. 70, n. 250, p. 651-690, 2010.

BRIONES, Claudia. (Meta)cultura del estado-nación y estado de la (meta)cultura. Brasília, DF: Universidad de Brasília, 1998.

CAM. Coordinadora Arauco-Malleco. El pensamiento emancipatorio de la Coordinadora de Comunidades Mapuche en Conflicto (CAM). Weftun, medio de comunicación oficial de la CAM, 2013. Disponible en: <https://www.weftun.org/ANALISIS/proyectopolitico.html>. Acceso en: 10 jun. 2017.

CAÑULEF, Eliseo. Introducción a la educación intercultural bilingüe en Chile. Temuco: Instituto de Estudios Indígenas / Universidad de La Frontera, 1998.

CHILE. Biblioteca del Congreso Nacional. Rodrigo Rojas: Chile debe modificar su modelo de exportación al Asia Pacífico. Programa Asia Pacífico, Santiago de Chile, 19 mar. 2014. Disponible en: <http://www.bcn. cl/observatorio/asiapacifico/noticias/rodrigo-rojas-acti>. Acceso en: 10 jun. 2017.

CHILE. Cámara de Diputados. Resumen ejecutivo 'Despliegue operativo institucional', para reunión Comisión Cámara de Diputados, 9 nov. 2015. 2015b. Disponible en: <https://www.camara.cl/pdf.aspx? prmID=40713\&prmTIPO=DOCUMENTOCOMISION>. Acceso en: 10 jun. 2017. 
CHILE. Cámara Marítima Portuaria. Desafíos de la conectividad para el comercio exterior: hacia una visión integradora del sector marítimo y portuario. Santiago de Chile: Cámara Marítima y Portuaria de Chile A.G, 2015.

CHILE. Consejo Nacional de Innovación para la Competitividad. Orientaciones estratégicas para la innovación: surfeando hacia el futuro. Chile en el horizonte 2025. Santiago de Chile: Consejo Nacional de Innovación para la Competitividad (CNIC), 2013a.

CHILE. Dirección Nacional de Orden y Seguridad. Comisión de Seguridad del Congreso Nacional, hechos asociados a Violencia Rural. Informe .n. VR-01 Al, 12 mar. 2016. Santiago de Chile: Dirección Nacional de Orden y Seguridad. Departamento de Análisis Criminal. Carabineros de Chile, 2016.

CHILE. Ministerio de Educación. Mensaje presidencial. 21 mayo 2014. Santiago de Chile: Ministerio de Educación, 2014.

CHILE. Ministerio de Educación. PEIB-ORÍGENES: estudio sobre la implementación de la educación intercultural bilingüe. Santiago de Chile: Ministerio de Educación, 2011.

CHILE. Ministerio de Planificación y Cooperación. Ley 19253 del 05 oct. 1993. Establece normas sobre protección, fomento y desarrollo de los indígenas, y crea la Corporación Nacional de Desarrollo Indígena. Santiago de Chile: Ministerio de Planificación y Cooperación, 1993. Disponible en: <https://www.leychile. cl/Navegar/scripts/obtienearchivo?id=recursoslegales/10221.3/3850/1/HL19253.pdf>. Acceso en: 10 jun. 2017.

CHILE. Ministerio de Relaciones Exteriores. Informe anual de comercio exterior de Chile 2014-2015. Santiago de Chile: Dirección General de Relaciones Económicas Internacionales: Ministerio de Relaciones Exteriores, 2015a.

CHILE. Ministerio de Transportes y Telecomunicaciones. Plan de impulso a la carga ferroviaria. Santiago de Chile: Logística. Subsecretaría de Transportes. Ministerio de Transportes y Telecomunicaciones, 2013b.

CHILE. Ministerio de Transporte y Telecomunicaciones. Plan nacional de desarrollo portuario. Santiago de Chile: Subsecretaría de Transportes. Ministerio de Transporte y Telecomunicaciones, 2013c.

CODELCO. Contesta oficio n5178 y n¹4175: adjunta nota GCNI nº 60/2016. Disponible en: <https:// www.camara.cl/pdf.aspx?prmTIP0=0FICIOFISCALIZACIONRESPUESTA\&prmID=64728\&prmNUMER0 =03 1\&prmRTE=4963>. Acceso en: 10 jun. 2017.

CONSEJO MINERO. Reporte Anual 2014. Santiago de Chile: Consejo Minero, 2015.

CORMA. Corporación Chilena de la Madera. Memoria anual 2014-2015. Santiago de Chile: Corma, 2016.

ESCOBAR, Arturo. Sentipensar con la tierra: nuevas lecturas sobre desarrollo, territorio y diferencia. Medellín: Unaula, 2014.

FOUCAULT, Michel. Arqueología del saber. Buenos Aires: Siglo Veintinuo, 2002. 
FOUCAULT, Michel. Defender la sociedad: curso en el Collège de France (1975-1976). Buenos Aires: Fondo de Cultura Económica, 2000.

FOUCAULT, Michel. La 'gubernamentalidad'. In: FOUCAULT, Michel. Estética, ética y hermenéutica. v. 3. Barcelona: Paidos, 1999. (Obras esenciales). p. 175-197.

FOUCAULT, Michel. Para una política progresista no humanista: respuesta a una pregunta [1968]. In: CASTRO, Edgardo (Ed.). ¿Qué es usted profesor Foucault? Sobre la arqueología y su método. Buenos Aires: Siglo Veintinuo, 2014c. p. 193-221.

FOUCAULT, Michel. ¿Qué es la arqueología? Entrevista con Michel Foucault [1971]. In: CASTRO Edgardo (Ed.). ¿Qué es usted profesor Foucault? Sobre la arqueología y su método. Buenos Aires: Siglo Veintinuo, 2014a. p. 267-287.

FOUCAULT, Michel. Seguridad, territorio, población. Curso en el Collège de France (1977-1978). México: Fondo de Cultura Económica, 2006.

FOUCAULT, Michel. Sobre la arqueología de las ciencias: respuesta al círculo de epistemología [1968]. In: CASTRO, Edgardo (Ed.). ¿Qué es usted profesor Foucault? Sobre la arqueología y su método. Buenos Aires: Siglo Veintinuo, 2014b. P. 223-265.

FUENZALIDA FIGUEROA, Gonzalo. Oficio 5178, 23 oct. 2014. Valparaíso: Cámara de Diputados de Chile, 2014. Disponible en: <https://www.camara.cl/pdf.aspx?prmTIPO=OFICIOFISCALIZACION\&prm ID=64728>. Acceso en: 10 jun. 2017.

FUENZALIDA FIGUEROA, Gonzalo. Oficio 14175, 17 nov. 2015. Valparaíso: Cámara de diputados de Chile, 2015. Disponible en: <https://www.camara.cl/pdf.aspx?prmTIP0=OFICIOFISCALIZACION\&prm $\mathrm{ID}=74220>$. Acceso en: 10 jun. 2017.

GARCÍA HUIDOBRO, Juan Eduardo; COX, Cristian. La reforma educacional chilena 1990-1998: visión de conjunto. In: GARCÍA HUIDOBRO Juan Eduardo (Ed.). La reforma educacional chilena. Madrid: Popular, 1999. p. 7-46.

HALE, Charles. ¿Puede el multiculturalismo ser una amenaza? Gobernanza, derechos culturales y política de la identidad en Guatemala. In: CALLA, Pamela; LAGOS, María (Ed.). Antropología del estado: dominación y prácticas contestatarias en América Latina. La Paz: INDH-PNUD, 2007. Informe Nacional sobre Desarrollo Humano. Programa de las Naciones Unidas para el Desarrollo. (Cuaderno de futuro; 23). p. 285-346.

HANNERZ, Ulf. Conexiones transnacionales: cultura, gente, lugares. Madrid: Cátedra, 1998.

KYMLICKA, Will. Estados multiculturales y ciudadanos interculturales. In: ZARIQUIEY, Roberto (Ed.). Realidad multilingüe y desafío intercultural. Lima: PUCP, 2003. p. 47-82.

LEPE-CARRIÓN, Patricio. Biopolítica borbónica en Chile: el discurso antropológico sobre la ociosidad y el vagabundaje. In: DÍAZ, Martín; PESCADER, Carlos (Ed.). Descolonizar el presente: ensayos críticos desde el sur. General Rocca: Publifadecs, 2012a. p. 231 -254. 
LEPE-CARRIÓN, Patricio. El contrato colonial de Chile: ciencia, racismo y nación. Quito: Universitaria Abya-Yala, 2016.

LEPE-CARRIÓN, Patricio. Intercultural education in Chile: colonial subjectivity and ethno-governmental rationality. Sisyphus, Lisboa, v. 3, n. 3, p. 60-87, 2015.

LEPE-CARRIÓN, Patricio. Reflexiones en torno a la instalación de la colonialidad en Chile. Evangelización, educación y reproducción de la 'diferencia colonial' en el siglo XVII. In: HENRÍQUEZ, Christian et al. (Ed.). Colonialidad/decolonialidad del poder/saber: miradas desde el sur. Valdivia: Universidad Austral de Chile, 2012b. p. 223-242.

LLAITÚL, Héctor; ARRATE, Jorge. Weichan: conversaciones con un weychafe en la prisión política. Santiago de Chile: Ceibo, 2012.

MARIMAN, José. Autodeterminación: ideas políticas mapuche en el albor del siglo XXI. Santiago: LOM, 2012.

MARIMÁN, Pablo et al. (Ed.). j--Escucha, winka--!: cuatro ensayos de historia nacional mapuche y un epílogo sobre el futuro. Santiago de Chile: LOM, 2006.

MBEMBE, Achille. Crítica da razão negra. Lisboa: Antígona, 2014.

ORTIZ, Andrés. Una de nuestras prioridades es garantizar un transporte de calidad y accesible para todas las personas. La Tercera, Santiago de Chile, ed. esp., p. 2, 10 jul. 2014. Disponible en: <http://www. contraloria.cl/prensa_cgr/litoral/2014/07/10_Noticias.pdf>. Acceso en: 10 jun. 2017.

PAIRICÁN Fernando; ÁLVAREZ Rolando. La Nueva Guerra de Arauco: la Coordinadora Arauco-Malleco y los nuevos movimientos de resistencia mapuche en el Chile de la Concertación (1997-2009). Revista Izquierdas, Santiago de Chile, v. 10, p. 66-84, 2011.

PEILLARD, Jacqueline. Informe sobre participación de parlamentarios en el IX Comité de diálogo político entre el Congreso Nacional y la Asamblea Nacional Popular China. In: CONGRESO NACIONAL Y LA ASAMBLEA NACIONAL POPULAR CHINA, Beijing y Hebei, 25 a 29 mayo 2015. Valparaíso: Cámara de diputados de Chile, 2015. Disponible en: <https://www.camara.cl/sala/verComunicacion. aspx?comuid=14823\&formato=pdf>. Acceso en: 10 jun. 2017.

PIZARR0, Jorge. La DC y el cobre. Periódico Tiempo 21, Temuco, 4-10 mar. 2016. 2016. Disponible en: $<$ https://issuu.com/tiempo21_ediciondigital/docs/377>. Acceso en: 10 jun 2017.

QUINTRIQUEO, Segundo et al. Formación del profesorado en educación intercultural en América Latina: el caso de Chile. Revista Electrónica Interuniversitaria de Formación del Profesorado, Zaragoza, v. 17, n. 2, p. 201- 217, 2014.

SELF BANK. La última inversión de moda: el grafeno. Madrid: Blog Self Bank, 2016. Disponible en: <http://blog.selfbank.es/la-ultima-inversion-de-moda-el-grafeno/>. Acceso en: 10 jun. 2017. 
STOLCKE,Verena. Talking culture: new boundaries, new rhetorics of exclusion in Europe. CurrentAnthropology, Chicago, v. 36, n. 1, spe. Issue, p. 1-24, 1995. Ethnographic authority and cultural explanation.

TAGUIEFF, Pierre-André. Las metamorfosis ideológicas del racismo y la crisis del antirracismo. In: ALVITE, Juan Pedro (Ed.). Racismo, antirracismo e inmigración: donostia: tercera prensa-gakoa, 1991. p. 143-204.

TRAPNELL, Lucy; NEIRA, Eloi. Situación de la educación intercultural bilingüe en el Perú. Lima: Banco Mundial: 2004. Consultoría solicitada por el Banco Mundial y PROEIB-Andes.

TUBINO, Fidel. La praxis de la interculturalidad en los Estados Nacionales Latinoamericanos. Cuadernos Interculturales, Valparaíso, v. 3, n. 5, p. 83-96, 2005.

VARESE, Stefano. Límites y posibilidades del desarrollo de las étnias indias en el marco del Estado Nacional. In: ARAVENA, Francisco Rojas (Ed.). América Latina: etnodesarrollo y etnocidio. San José de Costa Rica: Flacso, 1982. p. 149-160.

WALLERSTEIN, Immanuel; BALIBAR, Étienne. Raza, nación y clase. Madrid: lepala, 1991.

WILLIAMSON, Guillermo. Institucionalización de la educación intercultural bilingüe en Chile: notas y observaciones críticas. Perfiles Educativos, México, DC, v. 34, n. 138, p. 126-147, 2012.

WOLF, Edward L. Graphene: a new paradigm in condensed matter and device physics. Oxford: Oxford University Press, 2014.

Recibido en: 24.01.2017

Modificaciones en: 02.05.2017

Aprobado en: 20.06.2017

Patricio Lepe-Carrión es doctor en Filosofía por la Pontificia Universidad Católica de Valparaíso, Chile. Actualmente trabaja como investigador postdoctoral en el Núcleo de Ciencias Sociales y Humanidades de la Universidad de La Frontera, Chile; además, como becario de posdoctorado en la Universidad de Sao Paulo, Brasil; e investigador de la Universidad de Chile, como responsable del proyecto Fondecyt de Iniciación n011140804. 